Check for updates

The BMJ

nladher@bmj.com Follow Navjoyt on Twitter@NavjoytLadher Cite this as: BMJ2020;370:m3598 http://dx.doi.org/10.1136/bmj.m3598 Published: 17 September 2020

\section{Covid-19: Flying before we can walk}

\author{
Navjoyt Ladher head of education
}

In the week since The BMJ broke the story about the government’s Operation Moonshot plans to spend £1oobn on mass testing (p 337), ${ }^{1}$ we have seen a rising number of covid-19 cases and widespread reports of people struggling to access NHS Test and Trace. The UK still lacks a competent, functioning system to test, trace, and isolate cases of covid-19. It is hard to envisage how the ambitious proposals for mass testing could be realised when the current foundations are so shaky. How can we shoot for the moon when we are not getting the basics right?

Further analysis of the proposals does little to reassure. While increasing testing capacity is a laudable aim, there is almost no detail behind the headline grabbing figures. ${ }^{2}$ The Moonshot documents give no evidence of any careful analysis of the benefits, harms, and opportunity cost of a mass testing approach. Much of the testing technology has not been rolled out or fully evaluated and in some cases does not yet exist. ${ }^{3}$ Questions remain over where the operational capacity will come from and where this fits in the government's overall plan, assuming there is one.

"Big numbers will count for little without the right strategy," note Maggie Rae and Ellis Friedman, ${ }^{4}$ but time and again during the pandemic we have seen the government boast about world beating systems and big targets while failing to convey an overall coherent plan and end game. Operation Moonshot exemplifies the government's approach: a wildly ambitious standalone plan, light on detail, with little rooting in the reality of current capabilities, and planned for delivery through private contractors. Meanwhile, the basic tried and trusted approaches are still not being effectively delivered, and existing public structures continue to be overlooked.

The UK's poor track record on deaths from covid-19 suggests an urgent need for a different approach if we are to cope with a winter resurgence or second wave. ${ }^{5}$ The safety of healthcare workers is a major priority as we head into winter and a likely resurgence of covid-19. The BMJ has joined with the BMA to honour the memory of doctors who have died during the pandemic (bmj.com/covid-memorial). Their loss is a stark reminder of the risks faced by essential staff and of the disproportionate impact on ethnic minorities. Ensuring that all healthcare workers have proper personal protective equipment is one basic necessity we must get right.

1 lacobucci G, Coombes R. Covid-19: Government plans to spend f100bn on expanding testing to 10 million a day. BMJ2020;370:m3520. doi: 10.1136/bmj.m3520 pmid: 32907851

2 lacobucci G. Operation Moonshot: Leaked documents prompt questions over cost, evidence, and reliance on private sector. BMJ 2020;370:m3580doi: 10.1136/bmj.m3580.

3 Mahase E. Operation Moonshot: Testing plan relies on technology that does not exist. BMJ2020;370:m3585doi: 10.1136/bmj.m3585.

4 Rae M, Friedman E. Covid-19: An efficient and effective test trace regime is not a numbers game. BMJ2020;370:m3553doi: 10.1136/bmj.m3553.

Raleigh VSU. UK's record on pandemic deaths. BMJ2020;370:m3348. doi: 10.1136/bmj.m3348 pmid: 32887679

This article is made freely available for use in accordance with BMJ's website terms and conditions for the duration of the covid-19 pandemic or until otherwise determined by BMJ. You may use, download and print the article for any lawful, non-commercial purpose (including text and data mining) provided that all copyright notices and trade marks are retained. 